\title{
Microbial Quality of Locally Prepared Hibiscus Tea in Accra Metropolis, Ghana
}

\author{
${ }^{1}$ Billal Obeng Musah, ${ }^{2}$ Nicholas Israel Nii-Trebi, ${ }^{3}$ Maduforo Aloysius Nwabugo \\ ${ }^{2}$ Richard Harry Asmah \\ ${ }^{I}$ Noguchi Memorial Institute for Medical Research, University of Ghana, Accra, Ghana \\ ${ }^{2}$ School of Biomedical and Allied Health Sciences, College of Health Sciences, University of Ghana, Accra, \\ Ghana. \\ ${ }^{3}$ Department of Dietetics, School of Biomedical and Allied Health Sciences, College of Health Sciences, \\ University of Ghana, Accra, Ghana.
}

\begin{abstract}
Background Hibiscus tea is a tisane from the magenta coloured leaves of Roselle. It is widely known for its nutritional and therapeutic benefits. Food borne diseases are transmissible through consumption of contaminated food, drink and water. Locally prepared drinks may be potential sources of pathogenic bacteria, fungi and their toxins. The microbial safety of locally prepared Hibiscus tea Accra awaits investigation and documentation. This study was conducted to assess the microbial quality of locally prepared Hibiscus tea sold at the bus stations in Accra Metropolis, Ghana.
\end{abstract}

Method A total of 40 Samples of Hibiscus tea sold in either previously used or unused containers were collected, further processed and cultured on Plate Count Agar for Total Viable Count; then on Sabouraud Dextrose Agar for filamentous fungi; and on McConkey and Blood Agars for bacteria identification after 24-48 hours of incubation.

Results The microbial quality of Hibiscus tea packaged and sold in Used and Unused bottles was assessed in the Accra metropolis. The results did not find statistically significant evidence of health hazard from the Hibiscus tea samples analysed and therefore presents as acceptable for consumption.

Conclusion Findings show locally prepared Hibiscus tea as a potential source of microbial transmission due to the presence of various microbial contaminants found. Regular monitoring of the microbial quality and possible regulation by the appropriate authorities to safeguard public health is important.

Keywords: Microbial Quality, Hibiscus Tea, Accra

\section{Introduction}

Hibiscus tea is a tisane from magenta coloured leaves of Roselle, scientifically known as Hibiscus sabdariffa from the family Malvaceae [1]. It is known as Bissap in French-speaking West African countries, Sorrell in the Caribbean, Karkarde in Egypt and Sobolo in Ghana [2]. It is prepared by adding the magenta coloured leaves to two or three cups of water and boiling for about ten minutes to allow infusion. The leaves are then removed by sieving through a colander and preferably adding sugar and fruit flavours. The drink, taken either hot or cold, is widely known for its nutritional and therapeutic benefits [3]. It packaged in plastic bottles, refrigerated and sold. It serves as a source of income to some self-employed people in the developing world [4].

Food borne diseases are transmitted through consumption of contaminated food, drink or water. Improper washing of the Hibiscus leaves may introduce microbes into extracts leading to contamination of the product. Besides, use of unhygienic water for preparation, dressing with contaminated ice, improper storage, the use of unclean harvesting equipment, production in unclean surroundings and places where dust and flies are not properly controlled may also act as sources of contamination [5]. Consequently, the drink so prepared could be a potential source of transmission of microbial contaminants, notably Escherichia coli, Salmonella sp., Shigella sp., Staphylococcus aureus and some filamentous fungi. Some of these contaminants cause serious disease conditions like typhoid, dysentery, enteric fever and peripheral as well as systemic mycoses, which represent threats to human health[6,7].

Despite periodic quality control checks, outbreaks of diseases caused by pathogenic Escherichia coli, Salmonella sp., Shigella sp.. and some fungi are common. Even though there has not been a direct association of consumption of Hibiscus tea and outbreaks of such diseases, the recent outbreak of cholera in Accra during which over 200 cases were recorded within two weeks [8] underscores the need for regular monitoring of the microbial safety of food and drinks sold at public places, especially those prepared locally. 
In view of the appreciably high patronage for Hibiscus tea in Ghana and the need to help ensure its safe consumption, this study was conducted to describe the hygienic status of Hibiscus tea sold at the major bus stations in Accra Metropolis of Ghana.

\subsection{Study Area and Design}

\section{Methodology}

The study was experimental. Hibiscus tea samples were collected from different vendors at different bus stations, namely Tema, Circle and Kaneshie bus stations in the Accra Metropolis and analysed to determine the microbial quality of the locally prepared drink. Only Hibiscus tea in used and unused plastic bottles that had been refrigerated were sampled and analysed.

\subsection{Sample Collection}

A total of forty Hibiscus tea samples packaged in used and unused plastic bottles were collected for analysis. Twenty samples in previously used plastic bottles were collected from five vendors at the three bus stations. Twenty samples in new or previously unused plastic bottles with brand names were also collected. Each Hibiscus tea sampled was given a specific number which corresponded to the number for each media plate that was used for the analysis. Standard culture and biochemical techniques for the identification of bacterial and fungal pathogens were followed [9].

\subsection{Laboratory Procedures}

Standard procedures were followed in the counting and the identification of organisms for each of the forty (40) samples of Hibiscus tea. Microbial contamination was avoided by sterilization of all materials and strict adherence to aseptic techniques. Briefly, each sample of Hibiscus tea was diluted 1:10, $\left(10^{-1}\right)$, from which serial dilutions were made further to $10^{-4}$. One millilitre of each dilution (from $10^{-1}$ to $10^{-4}$ ) was pour-plated on pre-labelled plates of Plate Count Agar for Total viable count. The plates were then incubated at $37^{\circ} \mathrm{C}$ for 24 hours. After incubation, colonies on each plate for the respective dilutions were counted and the number multiplied by the corresponding dilution factor to obtain the Colony Forming Units per millilitre (CFU/ml) for each plate. The total $\mathrm{CFU} / \mathrm{ml}$ of a sample was calculated from the four dilutions made from that sample. Blood agar, McConkey agar and Sabouraud Dextrose agar were also inoculated to isolate fastidious bacteria, coliforms and fungi respectively. Confirmation of various bacterial pathogens were done by colonial morphology, Gram staining and biochemical tests.

Colonial morphology was done by examining and grouping the colonies based on the shape, colour, border, texture, and general appearance of an individual colony of bacteria on each plate. Gram staining was performed on the bacteria colonies and examined with $\times 100$ objective lens to identify the bacteria as Gram positive or Gram negative based on the staining properties. The Gram positive cocci bacteria were identified by Catalase and Coagulase tests. Biochemical tests such as Motility, indole, citrate, Urease, oxidase and fermentation tests were carried out to identify the particular Gram negative bacteria.

For fungi identification, samples were inoculated on Sabouraud Dextrose agar and incubated at $25^{\circ} \mathrm{C}$ for 3 days. Growth of fungi on the plate was recorded as Aspergillus sp. based on the shape, colour and staining characteristics with lactophenol cotton blue using the cellophane tape technique. Further, the pH of the samples were determined using a $\mathrm{pH}$ meter with buffer at room temperature to determine the acidity of the Hibiscus tea samples. All $\mathrm{pH}$ measurements were done after microbial analysis to prevent contamination of the samples. The electrodes were rinsed in the buffer and re-zeroed between measurements.

\subsection{Data Analysis}

The Food Standards Code for determining the microbiological quality of ready-to-eat foods, which categorizes food as acceptable, good and unsatisfactory based on levels of microbial load in foods shown in Table 1 below was employed in this study to determine the safety level of microbial contamination of the samples [10].

Table 1: Guideline levels for determining the microbiological quality of ready-to-eatfoods.

\begin{tabular}{llll}
\hline Standard plate count test & & $\begin{array}{l}\text { Microbial } \\
\text { Quality }(\text { CFU/ml, CFU/g) }\end{array}$ & \\
Food & Good & Acceptable & Unsatisfactory \\
\hline Category A & $<10^{4}$ & $<10^{5}$ & $\leq 10^{5}$ \\
Category B & $<10^{6}$ & $<10^{7}$ & $\leq 10^{7}$ \\
Category C & N/A & N/A & N/A \\
\hline
\end{tabular}

$\mathrm{N} / \mathrm{A}=$ Not Available 
Results obtained from the experiment were entered into a database and analysed statistically using Statistical Package for Social Sciences (SPSS) version 20 statistical software for windows and summaries were presented using descriptive statistics. The independent student T-test was used to determine significance difference between the Used and Unused mean viable counts. Probability value of $\mathrm{p}<0.05$ was considered as statistically significant difference.

\section{Results}

Out of the forty samples studied, seven different isolates were found, namely Aspergillus sp., Bacillus sp., Klebsiella sp., Pseudomonas sp., Streptococcus sp., Staphylococcus aureus and Escherichia coli. Table 2 shows the mean viable count (MVC) with standard deviation measured as CFU/ml, percentage distribution of contamination and the $\mathrm{pH}$ range for samples in Used and Unused bottles. Samples packaged in Used bottles were more contaminated, making up $54.6 \%$ of total contaminants found. There was statistically significant difference between the mean viable counts of samples packaged in Used and Unused bottles. The $\mathrm{pH}$ ranged between 2.0 and 5.2 for all the samples analysed.

Table 2: Mean Viable Count, Percentage distribution and $\mathrm{pH}$ range for Hibiscus tea samples packaged in both Used and Unused bottles.

\begin{tabular}{llll}
\hline Bottle type & Used bottle & Unused bottle & P - value \\
\hline Mean Viable Count & $5.27 \pm 0.87$ & $4.39 \pm 0.74$ & 0.001 \\
Percentage distribution $(\%)$ & 54.6 & 45.5 & \\
pH & $2.0-4.5$ & $2.4-5.2$ & \\
\hline Mean Viable Count values are presented as (Mean \pm Standard Deviation) $\times 10^{2} \mathrm{CFU} / \mathrm{ml}$.
\end{tabular}

Regarding occurrence of microbial isolates. Aspergillus sp. were the most predominant isolates, present in 14 out of 20 Unused bottles and 17 out of 20 used bottles (Table 3). Klebsiella sp. were the next predominant isolates, followed by Staphylococcus aureus, Escherichia coli, Pseudomonas sp., Bacillus sp. and Streptococcus $s p$. , the least found isolate.

Table 3: Frequency and Percentage (\%) occurrences of isolates in Hibiscus tea samples packaged in used and unused bottles

\begin{tabular}{lllll}
\hline Isolates & Unused bottles & Used bottles & Total & Percentage(\%) \\
\hline Bacillus $\boldsymbol{s p}$. & 8 & 10 & 18 & 12 \\
Klebsiella sp. & 11 & 15 & 26 & 17 \\
Pseudomonas $\boldsymbol{s p}$. & 10 & 9 & 19 & 13 \\
Streptococcus $\boldsymbol{s p}$. & 6 & 8 & 14 & 9 \\
S. aureus & 9 & 14 & 23 & 15 \\
E. coli & 7 & 13 & 20 & 13 \\
Aspergillus $\boldsymbol{s p}$ Total & 14 & 17 & 31 & 21 \\
Tot & $\mathbf{6 5}$ & $\mathbf{8 6}$ & $\mathbf{1 5 1}$ & $\mathbf{1 0 0}$ \\
\hline
\end{tabular}

The Gram staining reaction and biochemical identification of the bacteria isolates are shown in Table 4 . Gram positive, spore-forming rods, catalase-positive which had colonies to be dried, flat and irregular margins were identified as Bacillus sp. Red, mucoid and slightly raised colonies from McConkey agar plates that were Gram negative, indole-negative, citrate-positive and motility-negative were identified as Klebsiella sp. Gram negative rods, indole- negative, oxidase-positive and citrate-positive which had mucoid colonies with diffusible green pigment were identified as Pseudomonas sp. Gram positive, catalase-negative bacteria with circular colonies raised with depressed centres were identified as Streptococcus sp. Gram positive, catalase-positive, coagulase-positive with circular pinhead colonies were identified as Staphylococcus aureus; and Escherichia coli were identified by their red, mucoid and slightly raised colonies from McConkey plates that showed Gram negative, indole-positive and citrate-negative reactions.

Table 4: Gram stain reaction and biochemical identification of bacteria isolates

\begin{tabular}{|c|c|c|c|c|c|c|c|c|}
\hline Bacteria Identified & $\begin{array}{l}\text { Gram stain } \\
\text { reaction }\end{array}$ & Catalase & Coagulase & Motility & Indole & Citrate & Urease & Oxidase \\
\hline Bacillus sp. & + & + & - & - & - & - & - & - \\
\hline Klebsiella sp. & - & + & - & - & - & + & + & - \\
\hline Pseudomonas sp. & - & + & - & + & - & + & + & + \\
\hline Streptococcus sp. & + & - & - & - & - & - & - & - \\
\hline S. aureus & + & + & + & - & - & - & - & - \\
\hline E. coli & - & - & - & + & + & - & - & - \\
\hline
\end{tabular}

Key: No reaction (-), Reaction observed (+), species (sp.) 


\section{Discussion}

The microbial quality of locally prepared Hibiscus tea sold in some parts of Accra was assessed. The measured $\mathrm{pH}$ values for the samples analysed were in the range of 2.0-5.2. The acidic $\mathrm{pH}$ values observed for the drinks studied may be due to the acidic nature of the calyces used, the fermentation of carbohydrate in the fruit flavours or the sugar added to reduce the tartness of the drinks. Hibiscus calyces are found to be rich in organic acids such as phytic acid, oxalate, tannic acid, hydrocyanic acid and ascorbic acid. The calyces also contain phenolic compounds such as protocatechuic acid, chlorogenic acid and gallic acids $[11,12]$. In the preparation of Hibiscus tea for commercial purposes, a somewhat large amount of sugar is added to reduce the tartness. Sometimes fruit flavours rich in vitamins and minerals are also added to improve it nutritionally [13]. The sugar and fruit flavours added may undergo fermentation to cause a decrease in the $\mathrm{pH}$ of the drink. Therefore, the low $\mathrm{pH}$ range observed with the samples analysed may could arise from the combined effect of the acidic nature of the calyces, the fermentation of sugar and carbohydrate in fruit flavours used. It is important that measures be introduced in the preparation process to prevent too acidic drink product which could pose health harzards such as gastrointestinal disorders to consumers.

The mean viable counts for the sample packaged in used and unused bottles were $(5.27 \pm 0.87) \times 10^{2}$ $\mathrm{CFU} / \mathrm{mland}(4.39 \pm 0.74) \times 10^{2} \mathrm{CFU} / \mathrm{ml}$ respectively. There was a statistically significant difference between the two mean viable counts. This means that samples in used bottles were more contaminated than those in the unused bottles. This may be, among other possible causes of contamination, as a result of inefficient washing of the bottles or by the use of non-potable water in washing and/or inadvertent exposure of the washed bottles to contaminants prior to packaging. However, comparing the means obtained in the study and the reference range for microbial contamination of ready-to-eat foods in Table 1, the two means are below the microbial limits for ready-to-eat foods in category B foods under which Hibiscus tea falls. This means that the results are within expected microbiological levels for this type of product and makes it acceptable for consumption. The decreased mean viable counts of the samples analysed as compared to the reference guide could be attributed to the low $\mathrm{pH}$ range of the sample products. The acidic nature of the samples might make the environment (drink medium) unfavourable for many microbial contaminants to survive and thereby render the drink appreciably safe from threats of microbial pathogens. Furthermore, freezing and thawing could cause denaturation of cellular proteins and induce temperature shock in some micro-organisms, leading to decreased microbial load. [14].

This study, like a previous one found Aspergillus sp. to be the microbial contaminant with the highest occurrence (21\%) in both used and unused bottles [15]. This is of concern, in that the presence of fungi is associated with the production of Aflatoxin, which is heat stable and as such boiling does not have any effect on the potency of the toxin $[16,17]$. Furthermore, the toxin is carcinogenic and therefore the need to investigate the long term effect of continuous consumption of the locally prepared Hibiscus tea on human health. However, the fungal contamination of the drink and hence propensity for aflatoxicosis can be reduced or even averted by proper handling of the calyces and proper hygienic practices during preparation of the drinks. The need for proper handling and hygienic practices are underscored by the finding of various microbial contaminants which indicate human contact (S. aureus and Klebsiella sp.), water-borne (E. coli and Pseudomonas sp.), or use of sludge as manure (E. coli) and environmental sources of contamination (Bacillus sp.).

In view of the possible contamination and species heat stability, good manufacturing practices (GMPs), appropriate hygienic measures as well as brewing by boiling instead of cold water brewing should be preferred for enhanced consumption safety of locally prepared Hibiscus tea.

\section{Conclusion}

The study assessed the microbial quality of Hibiscus tea packaged and sold in Used and Unused bottles in the Accra metropolis. The results showed no statistically significant evidence of health hazard from the Hibiscus tea samples analysed. However, findings show locally prepared Hibiscus tea as a potential source of microbial transmission due to the presence of various microbial contaminants found. Regular monitoring of the microbial quality and possible regulation by the appropriate authorities to safeguard public health is important.

\section{Acknowledgements}

We would like to acknowledge Mrs. Richael Mills, Mr. Thomas Dankwah, Mr. John Nyarko, Ms. Safia Abdallah and the entire staff of the Microbiology Unit of Central Laboratory, Korle-Bu Teaching Hospital (KBTH), for their support and contributions during the work at the Laboratory. Special acknowledgement also goes to Mr. Jacob Arthur Quarm of Noguchi Memorial Institute for Medical Research (NMIMR), University of Ghana for the technical support throughout this study. 
[1] Morton, J., 1987. Roselle. p. 281-286. In: Fruits of warm climates. Miami, FL. http://www.hort.purdue.edu/newcrop/Morton/roselle.html.

[2] Nyarko, G., Bayor, H., Craigon, J., Suleimana, I.A., 2006. The Effect of container types, seed dressings and desiccants on the viability and vigour of Roselle (Hibiscus sabdariffa L.) seeds. Pak. J Biol Sci 9 (4), 593-597.

[3] Qi, Y., Chin, K. L., Malekian, F., Berhame, M., Gager, J., 2005. Biological haracteristics, nutritional and medicinal value of Roselle, Hibiscus sabdariffa. Circular- Urban Forestry Natural Resources and Environment, No. 604, March, 2005 , pp: 1-2.

[4] Fasoyiro, S. B., Ashaye, O.A., Adeola, A., Samuel, F. O., 2005. Chemical composition and storability of fruit-flavoured (Hibiscus sabdariffa) drinks. World J Agric. Sci. 1 (2), 165-168.

[5] U.S.A Food and Drug Administration, Centre for Food Safety and Applied Nutrition, 2001. Food safety. http//www.fda.gov. (Accessed on $5^{\text {th }}$ July, 2014).

[6] Barro, N., Bello, A.R., Aly, S., Ouattara, C. A. A., Ilboudo, A., Traore, A.S., 2006. Hygienic status and assessment of dishwashing waters, utensils, hands and pieces of money from street food processing sites in Ouagadougou (Burkina Faso). Africa J of Biotechnol 5(11), 1107-1112.

[7] Salle, A.J. 2000. Fundamental Principles of Bacteriology. TMH edition, Tata McGraw Hill Publishing Co. Ltd., New Delhi, 691699.

[8] Anonymous, 2012. Over 200 cholera cases recorded in Accra. Available: http//www.exposeghana.com (Accessed on 15 ${ }^{\text {th }}$ November, 2013)

[9] Cheesbrough, M., 2006. District Laboratory Practice in Tropical Countries. 2nd Edition, Cambridge University press, U.K. pp4570 .

[10] NSW Food Authority, 2009. Microbiological quality guide for ready-to-eat foods: a guide to interpreting microbiological results.Available: http://www.foodstandards.gov.au (Accessed on $6^{\text {th }} \mathrm{July}, 2014$ ).

[11] Adanlawo, I. G. and Ajibade, V.A.,2006. Nutritive value of two varieties of Roselle (Hibiscus sabdariffa) calyces soaked with wood ash. Pak J Nutr 5 (6), 555557.

[12] Ramierez-Rodrigues, M. M., Plaza, M. L., Azeredo, A., Balaban, M. O., Marshall, M. R., 2011. Physiochemical and phytochemical properties of cold and hot water extraction from Hibiscus sabdariffa. J Food Sci 76, 428-435.

[13] Fasoyiro, S.B., Babalola, S. O., Owosibo, T., 2004. Chemical composition and sensory quality of fruit flavoured (Hibiscus sabdariffa) drinks. pp. 1-8.

[14] Taura, D. W. and Habibu, A. U., 2009: Bacterial contamination of Lactucasativa,Spinaciaolerencea and Brassica olerencea in Kano Metropolis. Int J Biomed Health Sci 5(1).

[15] Ilondu, E. M. and Iloh, A. C., 2007. Inhibition of three fungal isolates from sorrel drink ("zobo") using hurdle technique. W orld J Agric Sci 3, 339-343.

[16] Adebayo-Tayo, B. C. and Samuel, U. A., 2000. Microbial quality and proximate composition of dried Hibiscus sabdariffa calyces in Uyo, Eastern Nigeria. Mal J Microbiol 5 (1), 13-18.

[17] Frazier, W. C. and Westhoff, D. C., 1998. Food Microbiology. 4th ed. International edition. Mc GrawHill, Singapore pp. 440441. 